\title{
A Noção de Estrutura na Gestaltpsychologie e na Epistemologia Genética: Usos e implicações para a psicologia
}

\author{
Joanneliese de Lucas Freitas ${ }^{1}$ \\ Universidade Federal do Paraná
}

\begin{abstract}
RESUMO - O presente trabalho expõe uma breve reflexão sobre as formas de apropriação do termo estrutura pela Gestaltpsychologie e pela Epistemologia Genética. Tem como objetivo traçar elementos para uma compreensão sobre o que se fala e a que se aplicam os sentidos do termo em ambas as teorias. Realizar esse percurso é buscar uma compreensão de como teorias e métodos se justificam em seus contextos epistemológicos e ontológicos. Conclui-se que não há uma unidade conceitual que permita generalizar o conceito de estrutura no campo psicológico, e que traçar seu caminho epistemológico auxilia na compreensão das relações, proximidades e diferenças entre os modelos explicativos utilizados e os problemas estudados.
\end{abstract}

Palavras-chave: estrutura, estruturalismo, Psicologia da Gestalt, Psicologia Genética

\section{The Concept of Structure in Gestaltpsychologie and Genetic Epistemology: Uses and implications for psychology}

\begin{abstract}
This paper presents a brief reflection on the ways Gestaltpsychologie and the Genetic Epistemology adopted the term 'structure'. It aims to describe valuable elements to understand what 'structure' means and how the term is used in both theories. Assume this path contributes to the search for an understanding of how theories and methods are justified in their ontological and epistemological contexts. It is concluded that does not exist a conceptual unit that allows generalizing the concept of structure in the psychological field. To trace its epistemological course it is useful to understand the associations, proximities and differences between the explanatory models of structure used and the problems studied.
\end{abstract}

Keywords: structure, structuralism, Gestalt psychology, Genetic Epistemology

Atravessando caminhos tortuosos, a psicologia enfrentou dificuldades próprias provenientes dos momentos epistemológicos pelos quais transitou. Não é de maneira linear nem tampouco única que abriu caminhos para construir-se enquanto saber. O movimento estruturalista foi um destes caminhos que se apresentou no campo das ciências humanas com relevantes repercussões para a construção teórica em psicologia.

A psicologia, no ocidente, sofre marcadamente reverberações desse movimento, porém, nem sempre claras ou facilmente distinguíveis. Na psicologia e nas ciências humanas, o termo estrutura é abundantemente difundido, apresenta diversos significados, muitas vezes com divergências consideráveis, produzindo não apenas indagações de ordem linguística, mas também de ordem epistemológica. Os prejuízos óbvios de tal polissemia encontram-se justamente em sua maior possibilidade de riqueza: sua variabilidade interpretativa. Tal variabilidade resulta não apenas em diferentes compreensões de um mesmo objeto, mas também em compreensões distintas sobre diversos objetos que se situam sob a égide de um substantivo

1 Endereço para correspondência: Praça Santos Andrade, 50, $2^{\circ}$ andar, sala 215, Centro, Curitiba, PR, Brasil. CEP: 80.020-300. E-mail: joanne@ufpr.br em comum, excluindo-se aqui questões sobre dissensões metodológicas. O problema, já antes apontado por Boudon (1974) e Bastide (1971), é que à polissemia do termo se soma uma variedade de noções outras a partir das quais se constituem as diferentes ideias de estrutura dentro de cada área do saber, o que tornaria a concepção indispensável não apenas à psicologia, mas também à economia, sociologia, linguística e antropologia.

O presente artigo tem como objetivo introduzir uma reflexão sobre o(s) conceito(s) de estrutura e suas possíveis relações e influências na psicologia. Realizar esse percurso é buscar uma compreensão de como teorias e métodos se justificam em seus contextos epistemológicos e ontológicos, bem como as relações entre os modelos teóricos e seus objetos de estudo. Foram escolhidas a Gestaltpsychologie e a Epistemologia Genética de Jean Piaget, pela envergadura e relevância de tais escolas dentro do campo psicológico. De um modo mais lato, entende-se que estrutura não se delineia como um conceito unificado, mas como uma ideia que subjaz e produz influências diversas em destacadas teorias das ciências humanas, assim como em teorias do campo "psi" bastante distintas e divergentes como, por exemplo, a Epistemologia Genética, a Psicologia da Gestalt ou Gestaltpsychologie e a Psicanálise Lacaniana. Mas estas escolas tratam da mesma "estrutura"? 


\section{Estrutura: de Ideia a Conceito}

Antes do advento do movimento estruturalista a palavra "estrutura" já existia no francês (Douville, 2009), bem como no português. Em nossa língua o vocábulo surgiu em 1769, derivado do latim structura, structurae (Cunha, 2012). Já os termos estruturação, estruturado, estrutural, estruturalismo, estruturalista e mesmo o verbo estruturar, surgiram apenas no século XX, como galicismos (Cunha, 2012). Segundo Faria (1991), em sua origem latina, structura é sinônimo ainda de expressões como fabricatio, constructio. Foi usada originalmente com um sentido de dispor em pilhas ou camadas, erigir, construir, edificar. A primeira derivação advém do verbo struo, struere. Derivação que devemos a Cícero, que em suas famosas catilinárias, acusou seu inimigo de struo, isto é, de tramar, preparar, maquinar contra a república.

Com a origem do movimento estruturalista na França, o termo foi assumindo acepções outras que influenciaram também a sua polissemia na língua portuguesa e na psicologia do século XX tal como pode ser constatado pelas datações e derivações da palavra (Cunha, 2012). Segundo Bastide (1971), o emprego do vocábulo começou a ser modificado na França ainda no século XVII, prosseguindo por uma dupla direção, que mais tarde influenciaria o surgimento das ciências ditas estruturalistas: primeiro, seu sentido avançou "em direção ao homem, cujo corpo pode ser comparado a uma construção (disposição dos órgãos, por exemplo), como o faz Fontenelle" (p. 2), e segundo, avançou "em direção às suas obras, em especial, à língua (distribuição das palavras na oração, composição de um estilo poético), com Balzac e Vaugelas" (p. 2). Bastide, porém, desconhecia o fato de que ainda quando o latim era língua viva, structurae, em um sentido figurado, já era utilizado para se referir ao arranjo das palavras na frase (Faria, 1991).

Há já aqui o esboço de dois caminhos originários para a compreensão do que seria uma estrutura, tal como concebido a partir do movimento estruturalista - o da biologia e o da matemática. O primeiro remete a estrutura ao que é previamente dado e à sua organização interna, o segundo a um sistema de leis que produzem um modelo em busca de uma inteligibilidade, arranjado segundo uma ordem significativa (Wolff, 1971). Mas é com a aparição do termo no campo sociológico, com Marx e Durkheim e depois com a linguística de Saussure, que temos o caminho do Estruturalismo aberto enquanto método e com objeto de conhecimento próprio (Douville, 2009).

A partir desse ponto, destacam-se três elementos concernentes às construções e aos sentidos do conceito, a saber: o fato de uma estrutura se constituir como um conjunto, as partes do conjunto e as relações entre tais partes (Bastide, 1971), ou ainda, uma totalidade auto regrada que produz diferentes combinações (Douville, 2009). A partir de então, o sentido de construção passa a descrever e ser ampliado por analogia aos seres vivos, para explicar seja seu corpo, sua língua, ou psique, porém em um campo complexo de articulações entre o dado e o constituído, entre uma organização natural e uma constituída. Entretanto, para realmente atingir os construtos teóricos das ciências sociais e da psicologia, percorreu-se um longo caminho:
A postura estrutural só se apossou verdadeiramente do campo das ciências humanas num segundo tempo, recente, a partir do século XIX, com Spencer, Morgan e Marx. Trata-se então de um fenômeno duradouro que combina de maneira complexa as várias partes de um conjunto numa acepção mais abstrata. (...) O estruturalismo nasce nos psicólogos para opor-se à psicologia funcional no começo do século ${ }^{1}$, mas o verdadeiro ponto de partida do método em sua acepção moderna na escala de todas as ciências humanas provém da evolução da linguística (Dosse, 1993, p. 15).

Encontramos, entretanto, referências ao termo ao buscálo na história da psicologia, mesmo antes de se formar uma dita ciência estruturalista (Bastide, 1971; Garcia-Roza, 1974). Tais referências, muitas vezes, remetiam mais à ideia de estrutura, na qual o conceito estaria anunciado, mas não organizado, tal como encontramos por exemplo na obra de Sigmund Freud (Sadala \& Martinho, 2011).

Dentro das várias áreas do conhecimento, percebemos um movimento do termo desde a biologia e da matemática para a sociologia, antropologia, linguística, e finalmente, percorre um caminho que leva à psicologia. Bastide (1971) afirma que mesmo antes do boom do uso da palavra estrutura, em 1930, quando seu sentido foi invadido por sentidos outros advindos dos novos conhecimentos adquiridos no campo da lógica e da matemática, esta já se encontrava mesclada a outra corrente, a dos "tipos ideais". Assim sendo, segundo Bastide (1971), “estas 'estruturas sociais' devem ser consideradas essencialmente mais como 'imagens ideais' do que como descrições de organizações empíricas” (p. 5). Definição que não se encontra distante da noção matemática de estrutura, a saber: "um sistema bem especificado de relações, ou de leis, que descrevem o funcionamento do fenômeno representado por um modelo" (p. 6). De fato, é notório que uma nova compreensão da biologia e da matemática construída no final do século XIX foi de enorme influência para a construção do conceito de estrutura em Lévi-Strauss, teórico de relevância capital para o estruturalismo nas ciências sociais, em que o marcante para a noção de estrutura são as relações construídas entre os objetos, como uma sintaxe, e não mais suas características intrínsecas (Almeida, 1999).

Contudo, foi com a linguística de Saussure que se tornou impossível o retorno de um caminho estruturalista com seu novo modo de compreender e se fazer ciências humanas. Seus desdobramentos na psicanálise e na antropologia são herança de uma formulação de estrutura enquanto relação entre os elementos, mas que não possui nem forma, nem significação, nem conteúdo (Douville, 2009).

Uma das primeiras definições para estrutura que encontramos em psicologia foi, segundo Lalande (1926/1999), uma "combinação dos elementos que a vida mental manifesta, considerada de um ponto de vista relativamente estático" (p. 347), que será sobreposto mais tarde pela definição estruturalista da Psicologia da Gestalt: "por oposição a uma simples combinação de elementos, um todo formado de fenômenos solidários, tais que cada um depende dos outros e só pode ser o que é na e pela sua relação com eles" (p. 347).

1 Século XX 
Percebe-se que a noção de estrutura adquire uma polissemia de sentidos tais como sistema, forma, organização, modelo, todo, desde que se tornou uma palavra em voga, assim como se tornou um recurso explanatório de várias ciências diferentes e de natureza bastante distintas, tais como, psicologia e matemática (Bastide, 1971; Boudon, 1974; Dosse, 1993). Tais explicações procuram, segundo alguns, por meio da construção de determinados modelos teóricos, investigar a universalidade de certos fenômenos e ainda, suprir uma necessidade metodológica pseudocientífica, procurando trazer às ciências humanas e sociais o tão almejado projeto cientificista (Peters, 2000). Segundo outra perspectiva, o estruturalismo seria justamente a forma de deslocamento dos padrões epistemológicos e metodológicos científico-naturalistas que ainda seriam a ordem do dia (Douville, 2009). Pensar nas categorias 'estruturas' teria sido uma forma de se construir um olhar novo sobre os objetos, distanciado, a respeito de suas simetrias e coordenadas. O estruturalismo foi, portanto, o coroamento da prática de se construir modelos como o modo de produção do conhecimento por excelência (Almeida, 1999), ou mesmo, a possibilidade de construção do pensar como um jogo de combinações. Talvez aqui esteja mais claramente dada sua herança matemática, estabelecendo-se o conceito de estrutura como uma definição por abstração, combinatória, onde as relações conceituais se sobrepõem às empíricas. Segundo Deleuze (1973/2000), tais jogos de combinações teriam efeito apenas no campo do simbólico, uma vez que o estruturalismo seria justamente, a descoberta ou o reconhecimento desse campo.

O problema de se colocar qualquer tipo de estrutura como explicação para uma questão investigativa é, especialmente nas ciências humanas e sociais, confundir uma ferramenta que utilizamos para entender a realidade com a própria realidade, criando assim, uma universalidade para processos humanos nem sempre universais. Ou em outros termos, utilizarmo-nos de definições conceituais para simplesmente resolver interrogações empíricas.

Diante de tantas possibilidades de sentido e de uso, perguntamo-nos: quais os sentidos de estrutura disseminados pela Epistemologia Genética e pela Gestaltpsychologie?

\section{Gestaltpsychologie: A Estrutura de Uma Forma e Suas Repercussões}

Como vimos, no corpo teórico da psicologia pode ser localizada uma grande influência de modelos estruturais derivados da biologia, da matemática e da linguística. Lagache (1971) afirma que entre as teorias psicológicas o termo estrutura "é uma maneira de designar a ideia de que as partes que se podem distinguir num conjunto mental mantêm entre si relações definidas" (p. 81) e que o problema seria para nós, psicólogos, justamente o modo de conceber a composição e a relação entre essas partes. Lagache relata que o uso de expressões relacionadas ao vocábulo estrutura foi introduzido nos EUA, no final do século XIX, por psicólogos interessados em reconstruir conjuntos mentais por meio da combinação de seus elementos, tais como, sensações, imagens e sentimentos, buscando resolver um problema epistemológico. Os maiores opositores dessa compreensão foram, à época, filósofos como Dilthey e Bergson. Sendo a filosofia de Bergson essencialmente uma filosofia da diferença, podemos perceber, juntamente com Deleuze (1966/1999), que "o que Bergson censura essencialmente a seus antecessores é não terem visto as verdadeiras diferenças de natureza" (p. 95), caracterizando um problema ontológico e não propriamente epistemológico. Ao tentar resolver a difícil questão sobre a unidade fundamental perdeu-se o olhar sobre a diferença e sobre o sujeito transcendental:

as ciências experimentais positivas são desde o início conduzidas por uma compreensão fixada dentro de seus "conceitos fundamentais", compreensão esta a maior parte do tempo não metódica e por assim dizer "instintiva", que adquire sua dignidade científica dentro da doutrina eidética do domínio do objeto em questão ou, em outras palavras, dentro da formação da ontologia material que lhe corresponde. Esta ontologia constitui a aquisição e a apropriação expressiva dos conceitos fundamentais, suscetiveis de "abrir os olhos" à pesquisa empírica fatual e de lhes dar de antemão um domínio circunscrito e um método² (Fink, 1974, pp. 21-22).

Segundo Garcia-Roza (1974), a dificuldade para se compreender a temática da estrutura em psicologia não está relacionada apenas a um caráter epistemológico, mas também ontológico, em que o comportamento seria, independentemente da mediação conceitual ou metodológica, estrutural. Em psicologia o termo estrutura adquire contornos mais precisos por meio do conceito de Gestalt, mais exatamente em 1890, com a publicação de Ehrenfels sobre as qualidades da forma.

Para Piaget (1968) a forma de maior relevo e mais "espetacular" do estruturalismo psicológico surgiria apenas em 1912 com a formalização da Gestaltpsychologie. Com o seu advento, o problema das estruturas e suas relações, com uma busca de explicações universais para fenômenos psicológicos, tomaria novo fôlego e novo foco. Segundo o autor, a ideia de estrutura a partir do olhar da Gestaltpsychologie esteve sob influência de modelos da física, especialmente no que concerne ao conceito de campo, tal como, por exemplo, percebe-se em Koffka (1975): "O campo físico é o campo do meio geográfico e nós mostramos que o comportamento deve ser explicado pelo meio comportamental. Será este, então, que constituirá o nosso campo psicológico?” (p. 54), pergunta o autor para responder logo a seguir: "não há mudança de movimento sem uma força. Será que esta determinação exclui o meio comportamental, como o nosso campo requerido? De maneira nenhuma" (p. 54).

Outra relevante influência sofrida pela Gestaltpsychologie foi a fenomenologia de Husserl, com seu modo de estudar o fenômeno humano por meio do método fenomenológico (Engelmann, 2002; Merleau-Ponty, 1973, 1996; Piaget, 1968, 1972/1991). Essas influências permitiram que a escola gestaltista rejeitasse as explicações que remetem apenas à análise de elementos simples e estáticos (imagem, sentimentos), assim como, aquelas que remetem às

2 Nossa tradução 
antinomias da psicologia (organismo/ambiente, passado/ presente), tentando se afastar de explicações simplistas ou de causalidade linear (Engelmann, 2002; Garcia-Roza, 1974; Köhler, 1947/1968; Lagache, 1971; Merleau-Ponty, 1973, 1996; Penna, 2000).

O termo estrutura concede, então, lugar ao termo Gestalt. A novidade da escola alemã foi postular e estudar relações de um todo organizado em um sentido não aditivo e em função de relações de equilíbrio (Engelmann, 2002; Holanda, 2009; Penna, 2000; Piaget, 1964/1988). Gestalt é uma palavra alemã que não possui tradução para outras línguas e que significa, segundo Engelmann (2002), "uma entidade concreta que possui entre seus vários atributos a forma" (p. 2).

Forma, tal como compreendida aqui, estaria sempre estruturada como uma totalidade onde o todo é anterior às partes e não simplesmente maior que a soma destas. Ao estabelecer a Gestalt como um todo estruturado e não estruturante, a Gestaltpsychologie aponta para o fato de haver elementos psicológicos previamente dados que, entretanto, tomam forma na qualidade (Gestaltqualität) e no presente, na atualidade - outro ponto que pode ser relacionado à influência fenomenológica (Koffka, 1975; Merleau-Ponty, 1973; 1996). Afirma-se que além de "agrupamentos aditivos, existem mesmo fatos físicos cujas partes se alteram em função do agrupamento, possuindo, portanto, características estruturais" (Garcia-Roza, 1974, p. 53).

O problema da escola de Berlin, ou da Psicologia da Gestalt, foi transformar uma experiência de percepção em leis universais e generalizáveis (Penna, 2000). E, ainda, ao buscar as essências, ou eidos da percepção, acaba por separar as essências ou intuições propostas por Husserl. Separa o vivido, desde onde nossos atos podem constituir objetos entre objetos psíquicos (nossas percepções) e sua causa objetiva (Gestalten) (Muller-Granzotto e Granzotto, 2004). Além disso, segundo Husserl, reduz as relações psicológicas a relações externas ou de simples fato - o que foi refutado por Koffka (Merleau-Ponty, 1973). Separar as essências e fixá-las em sua causa objetiva significa tomá-las como dados originais, mas não mais constitutivos. A Gestaltpsychologie se constituiria, assim, como um "empirismo das estruturas" (Penna, 2000, p. 38). Afastar as estruturas da atividade do sujeito é afastar-se da condição pré-dada de uma subjetividade transcendente, tal como propunha a fenomenologia.

O termo Gestalt, ainda carregado com os sentidos advindos do conceito anterior de estrutura, se tornou extremamente importante para o desenvolvimento de outras teorias psicológicas, tal como a teoria de campo de Kurt Lewin-também fortemente influenciada pela fenomenologia, matemática, topologia e física (Lewin, 1936; Garcia-Roza, 1974; Rodrigues, 1981). Lewin é considerado um dos autores mais influentes da psicologia da Gestalt, apresentado repercussões de suas ideias na construção da psicologia social, no humanismo americano e na perspectiva psicopatológica de Kurt Goldstein (Holanda, 2009; Moscovici, 1988; Piaget, 1968).

Principal fonte para numerosas investigações sobre dinâmica de grupos, Lewin $(1936,1948)$ apresenta uma abordagem estruturalista com uma perspectiva de compreensão dos pequenos grupos, a partir de uma análise topológica e qualitativa, tal como já encontrada anteriormente em autores como Koffka (1975). Segundo Lewin (n.d.), pode-se entender um grupo como "um "todo dinâmico"; isto significa que uma mudança no estado de qualquer subparte modifica o estado de todas as outras subpartes" (p. 100). Também o indivíduo era por ele considerado como uma complexidade e totalidade, desde que não destacado do grupo, isto é, o comportamento é entendido sempre em função do campo, sendo a ideia de campo compreendida como um todo de influências conexas, afetivas e intelectuais que afetam um dado comportamento quando se produz. Utilizando-se da teoria de campo psicológico de Koffka, Lewin (1936, 1948) introduz no trabalho com grupos a experimentação, aprofundando e articulando conceitos tais como espaço vital, região e forças de campo para explicar fenômenos como rigidez social, discriminação, personalidade e decisão de grupo. $\mathrm{O}$ conceito de estrutura aqui, adquire contornos operacionais, afastando-se de um caráter puramente teórico.

Nota-se que a Gestaltpsychologie permite a transição de uma ideia de estrutura como construção a priori, de um todo que se edifica como uma forma na qual os objetos se moldam, para uma ideia de todo onde as relações entre as partes são mais relevantes do que o resultado, a soma ou o conteúdo das estruturas, formando uma totalidade significativa. Tal apreensão se aproxima mais de uma concepção de sistema do que de estrutura tal como o estruturalismo francês propunha, com seu corte epistemológico pela inclusão do simbólico. É uma psicologia em busca da significação, mas de uma significação produzida "para além da distinção da atividade e da passividade" (Merleau-Ponty, 1973, p. 55), ou como dito anteriormente, é uma busca pela compreensão da qualidade.

Várias críticas à Gestaltpsychologie surgem precisamente no seio da psicologia, especialmente pelo olhar do estruturalista Jean Piaget. Ele é um dos principais autores que apesar de apontar ganhos relevantes para a psicologia com o advento da psicologia da Gestalt, levanta algumas críticas de peso e aponta as principais divergências entre a concepção de estrutura dessa teoria e uma perspectiva estruturalista.

\section{Jean Piaget: Seu Estruturalismo Genético e o Desenvolvimento Humano}

Piaget não é apenas um autor fortemente influenciado pelo movimento estruturalista, mas é amplamente reconhecido como representante de tal escola (Fortes, 2006; Nunes, 2011; Piaget, 1972/1991). O estruturalismo propõe uma concepção de estrutura que não tenha relação alguma com qualquer noção ou ideia de essência, uma forma sensível ou mesmo uma apreensão que apresente a estrutura como uma forma com certa pregnância entre suas partes, tal como proposto pela teoria gestaltista. Para a escola estruturalista, trata-se de uma combinação entre diferentes elementos formais que não possuem forma, significação, representação, conteúdo nem tampouco identidade empírica. Estrutura não se trata, portanto, nem de um modelo funcional hipotético, nem de uma inteligibilidade por detrás das aparências, mas sem dúvida está relacionada ao princípio de uma gênese (Deleuze, 1973/2000).

Piaget é um autor que no seio da psicologia se dedica a esclarecer a noção de estrutura, frequentemente em 
contraposição àquela de Gestalt, apresentando uma "virada" epistemológica no campo psicológico ao incluir a gênese e a temporalidade como problemas inerentes à compreensão das estruturas (Piaget, 1964/1988, 1968). O autor afirma que o conceito de Gestalt repousaria sobre "a esperança de possíveis matematizações ou fisicalismos" (Piaget, 1964/1988, p. 192) se apresentando como uma estrutura sem gênese, enquanto outras teorias, tais como as concepções americanas de aprendizagem, seriam psicologias genéticas sem estrutura.

Em uma de suas críticas mais severas à Gestaltpsicologie, Piaget (1968) afirma que ao entender o insight como um ato de inteligência, esta escola ignora o fato de que os atos que precedem o insight já se apresentam como inteligência, tal como uma estrutura. Outra crítica levantada pelo autor é a de que as percepções simplesmente não se desenlaçam na frente do sujeito, autonomamente, mas dependem de um sujeito ativo que constrói suas estruturas e está, portanto, implicado na percepção. Aqui, percebe-se a inclusão do sujeito epistemológico como um elemento novo e importante, além da dita "virada" genética do estruturalismo piagetiano: a introdução no campo da psicologia da noção de que as estruturas possuem uma gênese, o que segundo Nunes (2011) confere "frescor" à psicologia da época. Piaget defende, por exemplo, que as estruturas lógico-matemáticas, tais como os grupos, são de essência claramente aditiva, o que contraria o princípio básico da totalidade da Gestalt. E, por último, que a inteligência não é um problema de figuração perceptiva, como quiseram derivar Köhler e Wertheimer a partir do estudo da percepção (Piaget, 1964/1988, 1968).

Dentro da variada gama de sentidos de "estrutura", Piaget aponta três possibilidades de compreensão do termo: como pré-formação, onde apresentaria um caráter inato, estrutura com formação contingente, puramente histórica, o que considera incompatível com o próprio conceito, e simplesmente, como construção (Piaget, 1968). Para ele, o verdadeiro problema para se compreender o tema gira em torno da predeterminação e da construção. Sua opção é claramente a da perspectiva da estrutura como função de uma construção em que se relacionam elementos funcionais e estruturais, por meio da atividade do sujeito, em um processo de equilibração e reversibilidade. Diferentemente da unidade psicofísica proposta pelos psicólogos da Gestalt, Piaget (1964/1988) apresenta o aspecto biológico como a estrutura inicial que daria origem às posteriores cognitivas, figuradas pelo estágio sensório-motor, em uma clara contraposição ao inatismo e ao historicismo.

Para Piaget (1968), estrutura é definida como:

um sistema de transformações, que implica leis como sistema (por oposição às propriedades dos elementos), e que se conserva ou se enriquece pelo jogo mesmo de suas transformações, sem que estas cheguem além de suas fronteiras ou recorram a elementos exteriores. Em suma, uma estrutura compreende deste modo três ideias-chave: a de totalidade, de transformação e de autorregulação ${ }^{4}$ (p. 10).

3 Tradução nossa

4 Tradução nossa
Nota-se que a noção de desenvolvimento, para Piaget, contém as ideias de totalidade, transformação e autorregulação, apresentando o desenvolvimento de forma progressiva, bem como está relacionado a um processo de evolução biológica, mantendo a transmissão cultural e o uso de instrumentos ligados a estruturações biológicas por meio da ação do sujeito epistêmico (Freitas, 1999; Ford \& Lerner, 1992). O que é importante para compreender que as classificações estruturais são aplicadas aos comportamentos (ações) e não às pessoas (Abreu et al., 2010), como muitas vezes acontece com apropriações equívocas da teoria piagetiana.

Em seu projeto de psicologia, houve um entendimento de que desenvolvimento humano seria um processo regular e progressivo, assim como o é o biológico. Entretanto, Piaget estava interessado no estudo dos processos que implicam desenvolvimento e não meramente no desenvolvimento. $\mathrm{Ou}$ seja, seu problema tornara-se mais específico: os processos de construção das estruturas responsáveis pelo pensamento e pelo conhecimento do mundo e de si mesmo e não simplesmente as mudanças comportamentais dos sujeitos.

Em sua definição de estrutura, encontramos influência da biologia, da cibernética e da lógica, além de articulações claras e explícitas com o estruturalismo e assim também com a sociologia e a linguística (Piaget, 1972/1991). Apesar de buscar regularidades, Piaget coloca o sujeito epistêmico como ativo na construção de suas próprias estruturas, tentando fugir ao problema da sujeição às estruturas, sem conseguir, obviamente, escapar de suas determinações justamente pela contaminação de sua teoria pela noção de progresso (Freitas, 1999). A noção de progresso é controversa, posto que se relaciona com um telos, ou um objetivo final a ser atingido mediante as transformações desenvolvimentais, que seria nesse caso, o estádio das operações formais, ou a estrutura mais equilibrada para a qual caminha o desenvolvimento humano.

Entre as críticas comumente endereçadas à teoria Piagetiana estão aquelas que versam sobre uma suposta ausência da discussão dos elementos históricos e sociais em seu trabalho, por este sublinhar a construção em seus aspectos biológicos em detrimento dos sociais (La Taille, 1992; Dongo-Montoya, 2013), o que é contestado pela literatura (La Taille, 1992; Lajonquière, 1997; Ferreiro, 1998; DeVries, 1997). Apesar deste ser um debate antigo é ainda comum que esta questão seja levantada. A literatura aponta para um desconhecimento de obras de relevo do trabalho piagetiano que discutem o problema das relações sociais (Lajonquière, 1997; Dongo-Montoya, 2013).

Segundo Ferreiro (1998) Piaget tratava a sociedade nem como coisa nem causa, pois "uma coisa é invocar o social, e outra muito diferente é fazê-lo entrar na análise do fenômeno estudado" (p. 164), sendo o social um sistema de relações a ser estudado para que seus efeitos possam ser claramente distinguidos, não podendo ser tratado como um bloco ou uma generalização determinante. "O máximo que se pode dizer é que, de fato, Piaget não se deteve longamente sobre a questão, contentando-se em situar as influências e determinações da interação social sobre o desenvolvimento da inteligência" (La Taille, 1992, p. 11). Ou em outras palavras, os processos de 
assimilação e acomodação seriam processos dinâmicos que teriam lugar entre o natural e o cultural (Abreu et al., 2010).

Além de rejeitar concepções inatistas das estruturas de pensamento, como vimos anteriormente, segundo Lajonquière (1997) não pode ser esquecido o fato de que é na interação sujeito-objeto, intermediada pela ação, que se dá o caráter construtivo das estruturas, onde o meio não é tomado como uma realidade pré-constituída, com o papel de simples estimulador externo. A relação sujeito-objeto apresenta o social por meio de um objeto situado e não de um objeto como "simples coisa":

Desta forma, cabe concluir que aquilo a ser re-construido não é um conhecimento enquanto cópia de uma coisa pré-constituída nem a própria coisa, enquanto realidade heterogênea à inteligência, mas um conjunto de interações responsáveis pela existência intelectual dos objetos de conhecimento. O objeto é, em si mesmo, um fragmento das interações (Lajonquière, 1997, p. 141).

A Epistemologia Genética possui implicações para diversos campos da psicologia e da pedagogia, tanto teóricos quanto aplicados, tais como a compreensão de aspectos variados sobre o desenvolvimento humano e sobre processos de aprendizagem. Não há dúvidas quanto a disseminação do trabalho de Piaget no Brasil e em outros países no que concerne à compreensão da moralidade, da vida afetiva, cognitiva e simbólica dos sujeitos, entretanto, é curioso notar que apesar de ser um fervoroso defensor do estruturalismo, raramente Piaget é lembrado na literatura como um representante desta escola.

\section{Considerações Finais}

Nota-se que não há uma unidade conceitual que permita generalizar o conceito ou ideia de estrutura no campo psicológico. Esta é uma noção que apresenta uma herança linguística e histórico-conceitual que não aceita uma unidade de proposição sobre seu significado. Suas heranças históricas apontam para influências de teorias e campos do saber distintos que produzem impactos sobre o que se entende por estrutura e consequentemente o que se entende sobre o objeto estudado, bem como as práticas psicológicas daí derivadas.

Posto está que a polissemia do termo se relaciona a diversos momentos epistemológicos e a divergentes conteúdos e compreensões. Nota-se que em psicologia há um diálogo importante com outras áreas do conhecimento na construção de saberes, inclusive, como herdeira do estruturalismo francês, como testemunhamos nas teorias discutidas. Entretanto, o diálogo com outras áreas do conhecimento não significa tomar suas teorias e conceitos como próprios à psicologia, mas exigem um caminho longo e árduo de trabalho para os psicólogos e revelam a complexidade de nosso objeto. Assim, nos perguntamos: até que ponto os modelos estruturais nos auxiliam a lidar com o fenômeno psicológico? Em cada uma das teorias que abordam a questão das estruturas, teremos certamente, uma resposta que está vinculada ao que se chama de fenômeno psicológico, ou melhor colocado, ao que se entende como sendo seu objeto.

Seria possível elencarmos um objeto comum às psicologias? Talvez não o seja, assim como, portanto, não será possível tratar as diferentes concepções de estrutura de um mesmo modo, o que nos remete à pluralidade teórica e epistemológica já notória entre os psicólogos. Quiçá a questão aqui apresentada seja apenas mais um dos problemas teóricos da psicologia que se constituiu como uma área plural, transitando entre modelos de ciência extraordinariamente variados. Modelos estes que estão constantemente em divergências ontológicas e epistemológicas que de algum modo delimitam suas especificidades.

Os modelos são de fato importantes pois ao delimitarem ‘quem é o homem' determinam por implicação o que se sabe e o que é possível fazer com o homem e com os problemas que a ele se apresentam, sejam eles práticos, teóricos ou éticos. Este ponto faz emergir não apenas o tema da legitimidade mas também aponta para uma encruzilhada entre um saber e as normas que este permite fundamentar, ou entre seus conceitos teóricos e as questões práticas com as quais se defronta (Wolff, 2012).

A dificuldade mais importante que permanece em aberto, exemplificada com o termo estrutura, é o da relação existente entre o modelo e a experiência concreta ou entre o modelo explicativo e os problemas que se propõem a responder. As diversas compreensões que apresentam explicações estruturais em psicologia buscam aprofundar a compreensão da experiência do homem em relação ao mundo, seja por meio do estudo da percepção e da noção de campo na Gestaltpsychologie, seja por meio das noções de gênese, ação e sujeito epistêmico em Piaget. Entretanto, o que garante que o modelo teórico funciona da mesma forma e, portanto pode explicar o que é operatório, a experiência, ou mesmo o que acontece com as pessoas? Ou como nos aponta Eco (1968/1972), um modelo de explicação - não só - estruturalista pode incorrer no erro de provocar

um rápido deslize de uma concepção operatória à uma concepção substancialista; os modelos, elaborados como se fossem universais, funcionam universalmente, então, eles refletem uma substância universal que os garanta. (...) Mas porque nós afirmamos que aquilo que permite ofuncionamento do modelo tem a mesma forma do modelo? ${ }^{5}$ (Eco, 1968/1972, pp. 340-341).

A questão, pois, não é o conceito de estrutura per se, ou qualquer outro, porém, o seu uso. Para compreender seu uso, ou seja, do que se fala e a que se aplicam de fato as questões estruturais, é necessário compreender adequadamente as implicações da noção de estrutura por meio de sua história, dos seus modos de construção e das ideias às quais esteve atrelada. Realizar esse percurso é poder compreender como teorias e métodos, disciplinas e programas se justificam, para que não se confundam proposições sobre a natureza do homem com verdades científicas, pois tal confusão poderia nos manter em projetos de saber que sustentam que o objeto que queremos compreender teria a mesma forma de seus modelos de compreensão.

5 Tradução nossa 


\section{Referências}

Abreu, L. C., Oliveira, M. A., Carvalho, T. D., Martins, S. R., Gallo, P. R., \& Reis, A. O. A. (2010). A epistemologia genética de Piaget e o construtivismo. Revista brasileira de crescimento e desenvolvimento humano, 20, 361-366.

Almeida, M. W. B. (1999). Simetria e entropia: Sobre a noção de estrutura de Lévi-Strauss. Revista de Antropologia, 42(1-2), 163-197. doi:10.1590/S0034-77011999000100010.

Bastide, R. (1971). Usos e sentidos do termo estrutura - nas ciências humanas e sociais. São Paulo: EdUSP/Herder.

Boudon, R. (1974). Para que serve a noção de estrutura? Rio de Janeiro: Eldorado.

Cunha, A. G. (2012). Dicionário Etimológico da língua Portuguesa (4a ed). Rio de Janeiro: Lexikon.

Deleuze, G. (1999). Bergsonismo. São Paulo: Editora 34. (Originalmente publicado em 1966)

Deleuze, G. (2000). A quoi reconnait-on le structuralisme? In: Châtelet, F. (2000). Histoire de la Philosophie VIII: Le XX siècle (pp.299-335). Paris: Hachette. (Originalmente publicado em 1973)

Devries, R. (1997). Piagt's social Theory. Educacional Researcher, 26(2), 4-17.

Dongo-Montoya, A. O. (2013). Resposta de Piaget a Vygotsky: convergências e divergências teóricas. Educação \& Realidade, 38, 271-292. doi: 10.1590/S2175-62362013000100015.

Dosse, F. (1993). História do estruturalismo: O campo do signo. São Paulo: Ensaio.

Douville, O. (2009). A propos des enjeux contemporains du structuralisme. Psicologia \& Sociedade, 21(spe), 13-25. doi: 10.1590/S0102-71822009000400004.

Eco, U. (1972). La structure absente. Paris: Mercure de France. (Originalmente publicado em 1968)

Engelmann, A. (2002). A psicologia da Gestalt e a ciência empírica contemporânea. Psicologia: Teoria e Pesquisa, 18, 1-16.

Faria, E. (1991). Dicionário escolar latino-português. Rio de Janeiro: FAE, Ministério da educação, 6 ed.

Ferreiro, E. (1998). Sobre a necessária coordenação entre semelhanças e diferenças. In: Castorina, J. A., Ferreiro, E., Lerner, D., \& Oliveira, M. K. (1998). Piaget-Vygotsky: Novas contribuições par o debate ( $5^{\mathrm{a}}$ ed) (pp. 147-175). São Paulo: Ática.

Fink, E. (1974). De la phénoménologie. Paris: Éditions de Minuit.

Fortes, I. (2006). Estrutura e temporalidade na psicologia e na psicanálise. Ágora, IX, pp. 193-206.

Ford, D. H., \& Lerner, R. M. (1992). Developmental systems theory. Thousand Oaks, CA: Sage.

Freitas, J. L. (1999). Orientações para crença acerca do desenvolvimento moral na percepção de pais de classe média. (Unpublished master's thesis) Universidade de Brasília, Brasília.

Garcia-Roza, L. A. (1974). Psicologia estrutural em Kurt Lewin ( $2^{\mathrm{a}}$ ed). Petrópolis: Vozes.

Holanda, A. F. (2009). Princípios da Gestalt e a teoria da forma. Em: Tourinho, C., \& Sampaio, R. (Org.). Estudos em psicologia: Uma introdução (pp. 57-81). Rio de Janeiro: Proclama.

Koffka, K. (1975). Princípios de psicologia da Gestalt. São Paulo: Universidade de São Paulo e Cultrix.
Köhler, W. (1968). Psicologia da Gestalt (A. Cabral, Trans.). Belo Horizonte: Itatiaia. (Publicado originalmente em 1947)

Lagache, D. (1971). Estrutura em psicologia. In: Bastide, R. (Org.). Usos e sentidos do termo estrutura - nas ciências humanas e sociais (pp. 81-82). São Paulo: EdUSP/Herder.

Lajonquière, L. (1997). Piaget: notas para uma teoria construtivista da inteligência. Psicologia USP, 8(1), 131-142. doi: 10.1590/ S0103-65641997000100008.

Lalande, A. (1999). Vocabulário técnico e crítico da filosofia ( $\left.3^{\mathrm{a}} \mathrm{ed}\right)$. São Paulo: Martins Fontes (originalmente publicado em 1926)

La Taille, Y. (1992). O lugar da interação social na concepção de Jean Piaget. In: La Taille, Y., Oliveira, M. K., \& Dantas, H. Piaget, Vygotsky, Wallon - Teorias psicogenéticas em discussão (pp. 11-21). São Paulo: Summus.

Lewin, K. (n.d.). Problemas de dinâmica de Grupo (M. M. Leite, Trans.). São Paulo: Cultrix.

Lewin, K. (1936). Principles of topological psychology (F., Heider \& G. M. Heider, Trans.). New York: Mc Graw Hill.

Lewin, K. (1948). Resolving social conflicts. New York: Harper \& Brothers.

Merleau-Ponty, M. (1973). Ciências do homem e fenomenologia. São Paulo: Saraiva.

Merleau-Ponty, M. (1996). Le primat de la perception et ses conséquences philosophiques. Vendôme: Verdier.

Moscovici, S. (1988). Psychologie sociale (2 ${ }^{\mathrm{a}}$ ed). Paris: PUF.

Muller-Granzotto, M. J., \& Granzotto, R. L. (2004). Gênese fenomenológica da noção de Gestalt. Revista do X Encontro Goiano da Abordagem Gestáltica, pp. 69-82.

Nunes, B. (2011). Gênese e estrutura. Em: Pinheiro, V. S. (Org). Benedito Nunes: Ensaios Filosóficos (pp. 262-268). São Paulo: Martins Fontes.

Penna, A. G. (2000). Introdução ao gestaltismo. Rio de Janeiro: Imago.

Peters, M. (2000). Pós-estruturalismo e filosofia da diferença. Belo Horizonte: Autêntica.

Piaget, J. (1988). Genèse et structure en psychologie de l'intelligence. In: Piaget, J. Six études de psychologie (pp. 191-210). France: Denoël. (Original publicado em 1964)

Piaget, J. (1968). El estructuralismo. Buenos Aires: Proteo.

Piaget, J. (1991). Psicologia e epistemologia (M. F. Bastos \& J. G. Bastos, Trans.). Lisboa: Dom Quixote. (Original publicado em 1972)

Rodrigues, A. (1981). Psicologia social. Rio de Janeiro: Vozes.

Sadala, G., \& Martinho, M. H. (2011). A estrutura em psicanálise: Uma enunciação desde Freud. Ágora: Estudos em Teoria Psicanalitica, 14, 243-258. doi:10.1590/S151614982011000200006.

Wolff, E. (1971). Uso e significado da palavra "Estrutura" em biologia. In: Bastide, R. (Org.). Usos e sentidos do termo estrutura - nas ciências humanas e sociais (pp. 15-20). São Paulo: EdUSP/Herder.

Wolff, F. (2012). Nossa humanidade: De Aristóteles às neurociências. São Paulo: Editora Unesp.

Recebido em 06.03.2014 Primeira decisão editorial em 09.07.2014 Versão final em 19.08.2014 Aceito em 23.09.2014 